\title{
Ensaios Dinâmicos não Destrutivos em Estacas Hélice Contínua - PIT (Pile Integrity Test): Estudo de Caso de Obra em Canoas/RS
}

\author{
J. Sebben ${ }^{1 *}$, H. Z. Ehrenbring; F. Pacheco; R. Christ; C. Simonetti \\ *Autor de Contacto: engsebben@gmail.com (marcado con un asterisco entre los autores) \\ ${ }^{1}$ Especialização em patologia e perícia das edificações, Universidade do Vale do Rio dos Rio dos Sinos, São \\ Leopoldo, Brasil.
}

\begin{abstract}
RESUMO
As fundações são constituídas por elementos estruturais, tendo como função principal transmitir as cargas da supraestrutura ao solo, contribuindo na estabilidade de edificações. Sendo assim, este trabalho objetiva aferir as incidências patológicas que poderão advir junto às fundações do objeto de estudo, que são torres habitacionais de um empreendimento em Canoas-RS. Utilizou-se ensaios Pile Integrity Test (PIT) realizados in loco. Logo, a metodologia empregada compreendeu a análise das sondagens, dos relatórios das estacas hélice contínua e a avaliação dos ensaios dinâmicos não destrutivos, de maneira a determinar um comportamento padrão no que se refere às anomalias, bem como explanar as causas face às falhas construtivas identificadas in loco, caracterizando o PIT como uma estimativa acerca das propriedades dos elementos ensaiados.

Palavras-chave: Estacas hélice contínua; Pile Integrity Test; Controle de qualidade de fundações; Reduções de impedância; Ensaios dinâmicos não destrutivos em fundações
\end{abstract}

\section{RESUMEN}

La cimentación está formada por elementos estructurales, cuya función principal es transmitir las cargas desde la superestructura al suelo, contribuyendo a la estabilidad de las edificaciones. Así, este trabajo tiene como objetivo evaluar las posibles incidencias patológicas encontradas que puedan surgir a lo largo de los cimientos del objeto de estudio, que son las torres de viviendas de un proyecto en Canoas-RS. Se utilizaron las pruebas Pile Integrity Test (PIT) realizadas in loco. Por tanto, la metodología empleada incluyó el análisis de perforaciones, informes de pilotes helicoidales continuos, control tecnológico de hormigón y evaluación de ensayos dinámicos no destructivos, con el fin de determinar un comportamiento estándar con respecto a las anomalías, así como explicar las causas de cara de las fallas constructivas identificadas in loco, caracterizando al PIT como una estimación sobre las propiedades de los elementos probados.

Palabras clave: Estacas hélice continua; Pile Integrity Test; Control de calidad de cimentaciones; Reducción de impedancia; Ensayos dinámicos no destructivos en cimentaciones. 


\section{INTRODUÇÃO}

As fundações são definidas como elementos estruturais cuja função consiste em transmitir as cargas da estrutura ao solo e, assim, compreende-se a sua importância. Logo, o desempenho das fundações se encontra relacionado ao comportamento dos solos, que por obterem ampla distinção de características físicas e químicas, respondem de maneira muito variável, o que legitima a importância das análises em tais elementos. (AZEREDO, 1977)

Diante disso, Velloso e Lopes (2011) ressaltam que a verificação de desempenho em obras de fundação se transfigura a mais difícil de realizar, visto a complexidade e a heterogeneidade dos solos. Soma-se a isso o fato de tais estruturas serem consideradas não manuteníveis em virtude da dificuldade de acesso, conforme classifica a NBR 15575-1 (ABNT, 2013).

Sendo assim, o controle rígido de qualidade durante os processos executivos de fundações deve ser implantado visando a neutralização ou então, a redução de manifestações patológicas decorrentes desta etapa, que independentemente dos carregamentos, índice de esbeltez das estruturas ou finalidade ocupacional, são de suma importância para o bom funcionamento da interação solo-estrutura.

Considerando esse cenário, este trabalho teve como objetivo analisar as causas das possíveis incidências patológicas identificadas na obra de estudo a partir de ensaios de integridade PIT (Pile Integrity Test), dispondo como sustentáculo técnico e metodologia a análise das sondagens SPT (Standard Penetration Test), projetos de fundações, relatórios de estacas hélice contínua monitoradas, ensaios de resistência axial de corpos de prova de concreto, bem como os resultados das provas de cargas executadas sobre as estacas, as quais são compostas por estacas hélice continua.

\section{FUNDAÇÕES}

O projeto e a execução de fundações demanda por conhecimentos de geotecnia e cálculo estrutural, compreendendo a análise estrutural e o dimensionamento de estruturas em concreto armado, elementos em aço ou estruturas de madeira, os quais se encontram em contato com o solo. (VELLOSO E LOPES, 2010).

De acordo com Milititsky, Consoli e Schnaid (2008), os custos dos sistemas de fundação divergem de acordo com as cargas e das condições do subsolo. Entretanto, usualmente, estes estão situados na faixa de 3 a $6 \%$ do custo total da obra. Ainda, o custo compreendido na execução de sondagens de reconhecimento do subsolo, normalmente, varia entre $0,2 \%$ e $0,5 \%$ do custo total de obras convencionais, este podendo ser expandido em casos de obras especiais ou condições adversas do subsolo, visto que, nestes casos, há necessidade de implantação de maiores investigações para o detalhamento das características do solo (SCHNAID E ODEBRECHT; 2012).

Ainda que esse custo de investigação seja reduzido e que ocorra a demanda por um projeto de fundações, Milititsky, Consoli e Schnaid (2008) ressaltam que a investigação e a interpretação de resultados são as causas mais frequentes de problemas encontrados em fundações.

Dessa maneira, o Código Europeu (Eurocode 7, 1997) preconiza que a caracterização geotécnica deve ser precedida de uma classificação preliminar, a qual pode ser dividida em três categorias, respectivamente: 
a) Categoria I: estruturas simples e de pequeno porte, onde o projeto é baseado em experiência e investigação geotécnica qualitativa.

b) Categoria II: estruturas convencionais que não envolvam riscos excepcionais, em condições geotécnicas normais e cargas dentro de padrões conhecidos.

c) Categoria III: estruturas de grande porte associadas a risco elevado, dificuldades geotécnicas excepcionais, cargas elevadas e eventos sísmicos, entre outros fatores.

Ademais, Velloso e Lopes (2010) definem as etapas de investigações em três grupos, sendo estes representados pelas etapas preliminares, complementares, de projeto, bem como as etapas provenientes da fase de execução. Perante o exposto, na investigação preliminar o objetivo consiste em obter o conhecimento das principais características do subsolo, sendo, em geral, executados somente ensaios à percussão. É importante ressaltar, por outro lado, que se excedem os casos em que há o conhecimento de que blocos de rocha precisam ser ultrapassados na investigação, quando, assim, solicitam-se sondagens mistas (HACHICH ET. AL., 1998).

A investigação complementar procura esclarecer os aspectos relevantes do subsolo, bem como caracterizar as propriedades do solo de maior importância referente ao comportamento das fundações. Nesta fase, são executadas mais algumas sondagens, fazendo com que o total atenda às normas técnicas vigentes e, eventualmente, realizam-se sondagens mistas ou especiais para a retirada de amostras indeformadas.

Por fim, quanto à investigação para a fase de execução, esta deve ser indicada tanto pelo projetista de fundações como pelo engenheiro executor da obra, de modo a ratificar os dados de projeto. Nessa etapa, podem ser necessários ensaios complementares (VELLOSO E LOPES, 2004).

Sobre os ensaios geotécnicos, Hachich et. al (1998) referem que a obtenção de amostras para ensaios de solo, bem como a identificação e classificação de solos exige a execução de ensaios "in situ”. No entanto, a determinação de propriedades de engenharia, tanto pode ser feita através de ensaios de laboratório, quanto em campo. Os autores também destacam que, na prática, há ampla prevalência dos ensaios "in situ”, estando a investigação laboratorial restrita à casos especiais em solos coesivos.

Schnaid e Odebrecht (2012) salientam que a análise dos resultados quanto a um projeto geotécnico pode ser realizada através de duas abordagens distintas:

a) Métodos diretos: de natureza empírica ou semiempírica. Baseia-se em obras geotécnicas ou dados estatísticos. O SPT se estabelece como o mais conhecido exemplo brasileiro de uso de métodos diretos de previsão, o qual é aplicado tanto para a estimativa de recalques, quanto para prever a capacidade de carga do solo.

b) Métodos indiretos: os resultados de ensaios são aplicados às previsões de propriedades constitutivas do solo. Pode-se exemplificar este método através dos ensaios de palheta e pressiométricos, nos quais algumas simplificações são passíveis de interpretação analítica, uma vez que a cravação de um cone em depósitos argilosos pode ser apurada através de abordagens numéricas.

Em consideração a isso, verifica-se que a escolha da abordagem (direta ou indireta) depende da técnica de ensaio utilizado, do tipo de solo investigado, de normas e códigos específicos, assim como as práticas regionais. Geralmente, o uso de uma abordagem semiempírica exprime a dificuldade em modelar as complexas condições de contorno decorrentes do processo de penetração e carregamentos oriundos do ensaio (SCHNAID E ODEBRECHT, 2012).

Segundo Hachich et al. (1998) ao se realizar uma sondagem pretende-se conhecer o tipo de solo, sua resistência e o nível da água. No Brasil, a NBR 8036 (ABNT, 1983) define o número mínimo de sondagens, onde a localização em planta no que diz respeito às edificações depende do tipo de estrutura, de suas características especiais, assim como das condições geotécnicas do subsolo. Sendo assim, de acordo com a NBR 8036 (ABNT, 1983), as sondagens devem ser constituídas de, 
no mínimo, uma para cada $200 \mathrm{~m}^{2}$ da área de projeção em planta da edificação, método que se ramifica até $1200 \mathrm{~m}^{2}$ de área construída. Entre $1200 \mathrm{~m}^{2}$ e $2400 \mathrm{~m}^{2}$ de área edificada, incumbe-se realizar uma sondagem para cada $400 \mathrm{~m}^{2}$ que excederem $1200 \mathrm{~m}^{2}$. Acima de $2400 \mathrm{~m}^{2}$, deve-se fixar o número de sondagens de acordo com o plano particular da construção.

No que se refere aos ensaios, o SPT ("ensaio de penetração dinâmica"), regido pela NBR 6484 (ABNT, 2020) mede a resistência do solo ao longo da profundidade perfurada. De acordo com Velloso e Lopes (2010), este tipo de sondagem é capaz de atravessar solos relativamente compactos ou duros. No entanto, as sondagens à percussão possuem por limitação a presença de rochas e/ou matacões, assim como possuem dificuldade em atravessar solos saprólitos.

Perante o exposto e, consequentemente, cessando a análise dos solos, introduz-se os procedimentos executivos. Assim, Velloso e Lopes (2010) definem que um dos problemas frequentemente encontrados na prática de estaqueamentos consiste na verificação da integridade da estaca após sua execução. O PIT corresponde a um teste de integridade não destrutivo para fundações, o qual requer um mínimo impacto decorrente de um martelo posicionado sobre o elemento que será ensaiado, o qual inclui o posicionamento de um acelerômetro de alta sensibilidade. Através deste, são deferidos golpes e verificadas as ondas de deformação no elemento ensaiado, cuja velocidade de propagação é registrada pelo acelerômetro e armazenada em um computador portátil. (RAUSCHE, F.; LIKINS G.; KUNG S. R.; 1992-2016).

No que diz respeito aos resultados, os fatores que impactam diretamente nos mesmos são o concreto (idade, resistência, homogeneidade), o tipo de solo e a interação deste com a estaca. Durante os procedimentos executivos, os fustes podem estar sujeitos à redução de seção, alargamento ou então, a contaminação de seu interior com o próprio solo adjacente. Desta forma, a combinação de dois ou mais fatores destes citados podem influenciar o sinal registrado pelo acelerômetro, acarretado, assim em uma variação de impedância. (RAUSCHE, F.; LIKINS G.; KUNG S. R.; 1992-2016)

Ainda, nesse contexto, há o ensaio PDA ("Prova de Carga Dinâmica"), que calcula a capacidade de carga de uma estaca considerando medições de força e velocidade. A força é obtida por meio de sensores de deformação, cujo sinal é multiplicado pelo módulo de elasticidade do material e pela área de seção avaliada (HACHICH et al. 1998). Alonso (1991), define que a prova de carga é dinâmica, dado que a carga mobilizada em cada golpe é medida pela monitoração do golpe, ou a partir da interpretação da curva deslocamento x tempo.

Hachich et al. (1998) também citam que estes ensaios são utilizados, principalmente, para a verificação do desempenho de fundações no que diz respeito à possíveis rupturas e recalques, o que vai ao encontro com Velloso e Lopes (2010), que frisam que as provas de carga dinâmicas são realizadas em estacas (e tubulões) possuindo os seguintes objetivos: a verificação quanto ao comportamento previsto em projeto (capacidade de carga e recalques) e a definição da carga de serviço em casos em que não se consiga prever o comportamento da estaca quando esta for solicitada.

\section{MÉTODOS}

\subsection{Estudo de caso}

A obra analisada realizou uma série de ensaios não destrutivos PIT, através dos quais percebeu-se o acúmulo de reduções de impedância em múltiplas estacas, sendo esta definida, segundo Junior (2017), como a resistência oferecida pelo meio à propagação da onda na medida em que ocorreu, na ocasião, o ensaio de integridade PIT sobre as estacas em concreto armado. Sendo assim, em alguns lotes de testes, o montante de discrepâncias acusados foi superior a 40\%, demandando o parecer do projetista ou então, a implementação de novos testes investigativos a fim de ratificar a estabilidade estrutural da obra, em concordância com o projeto concebido. 
Diante disso, investiga-se também a possibilidade de manter a sequência executiva (cronograma) dos elementos de fundações da obra em questão ou então, se há necessidade de implementar medidas corretivas, tal qual a execução de reforços estruturais para os elementos que apresentam as possíveis incidências patológicas, estas representadas pelas reduções de impedância no ensaio PIT. Portanto, com base nisso, a figura 1 denota os procedimentos executivos realizados na obra de estudo.

Figura 1: Perfuratriz e caminhão bomba na obra de estudo - compreendendo a execução de fundações em estacas hélice contínua monitorada

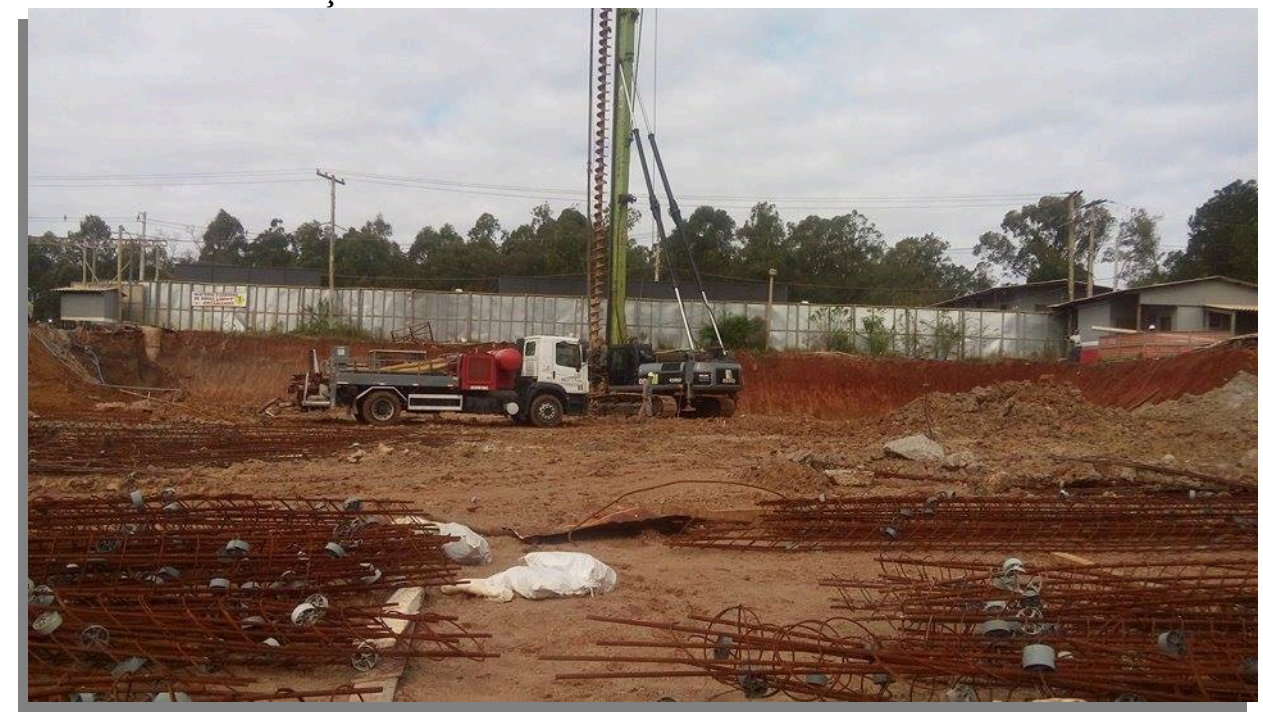

Então, referente à obra de estudo, a concepção do projeto de fundações das torres contempla estacas do tipo hélice contínua, cujos diâmetros nominais são de 400, 500 ou $600 \mathrm{~mm}$, possuindo uma profundidade média de $18 \mathrm{~m}$. Estas estacas estão interligadas em sete tipos de blocos de coroamento, os quais podem possuir entre uma e nove estacas sob eles.

Além disso, na obra de estudo, buscou-se analisar as geometrias dos blocos de coroamento em que as estacas estavam contidas, para que, assim, possa-se buscar possíveis vícios construtivos durante o processo executivo destas, de maneira a aferir, através de uma engenharia reversa e análise estatística, se os limites das distâncias de concretagens (na mesma data) das estacas tipo hélice contínua foram respeitadas.

Logo, diante da situação apresentada, visa-se, neste presente trabalho, analisar as estacas que apresentaram discrepância em testes do PIT ou PDA junto às torres "B" e "D", estas que, por sua vez, obtiveram os maiores índices de reduções de impedâncias durante os ensaios PIT na obra de estudo

\subsection{Ensaios de PIT (pile integrity test) e de PDA}

O ensaio de PIT foi realizado em todas as estacas da obra, caracterizando, dessa forma, uma amostragem total. Na obra estudo de caso foram realizados os ensaios de PDA em 3\% das estacas executadas 


\section{RESULTADOS}

\subsection{Redução de impedância em estacas}

A torre "B" e periferias (área composta pelos estacionamentos) possuem 337 estacas, enquanto a torre "D" e periferias somam 328 estacas. Entre as torres analisadas, a torre "D" computou o maior número de reduções de impedâncias e, consequentemente, maior percentual de incidências no comparativo com a torre "B". Conforme as tabelas 1 e 2, pode-se verificar as ocorrências supramencionadas, bem como os percentuais em ambas as torres, onde a Tabela 1 representa as ocorrências na torre "B", enquanto a tabela 2 apresenta as mesmas para a torre " $\mathrm{D}$ ".

Tabela 1. Ocorrência de reduções de impedâncias na torre "B" e periferias

\begin{tabular}{|c|c|c|c|}
\hline \multicolumn{4}{|c|}{ REDUÇÕES DE IMPEDÂNCIA DO ENSAIO PIT - TORRE B } \\
\hline $\begin{array}{c}\boldsymbol{\phi} \text { ESTACA } \\
\text { (cm) }\end{array}$ & $\begin{array}{c}\text { QUANT. } \\
\text { TOTAL DE } \\
\text { ELEMENTOS }\end{array}$ & $\begin{array}{c}\text { QUANT. DE } \\
\text { INCIDÊNCIAS }\end{array}$ & $\begin{array}{c}\text { (\%) DE } \\
\text { INCIDÊNCIAS }\end{array}$ \\
\hline 40,00 & 147,00 & 15,00 & $10,20 \%$ \\
\hline 50,00 & 103,00 & 20,00 & $19,42 \%$ \\
\hline 60,00 & 87,00 & 0,00 & $0,00 \%$ \\
\hline TOTAL: & $\mathbf{3 3 7 , 0 0}$ & $\mathbf{3 5 , 0 0}$ & $\mathbf{1 0 , 3 9 \%}$ \\
\hline
\end{tabular}

Tabela 2. Ocorrência de reduções de impedâncias na torre " $\mathrm{D}$ ” e periferias

\begin{tabular}{|c|c|c|c|}
\hline \multicolumn{4}{|c|}{ REDUÇÕES DE IMPEDÂNCIA DO ENSAIO PIT - TORRE D } \\
\hline $\begin{array}{c}\varnothing \text { ESTACA } \\
\text { (cm) }\end{array}$ & $\begin{array}{c}\text { QUANT. } \\
\text { TOTAL } \\
\text { ELEMENTOS }\end{array}$ & $\begin{array}{c}\text { QUANT. DE } \\
\text { INCIDÊNCIAS }\end{array}$ & $\begin{array}{c}\text { (\%) DE } \\
\text { INCIDÊNCIAS }\end{array}$ \\
\hline 40,00 & 135,00 & 36,00 & $26,67 \%$ \\
\hline 50,00 & 105,00 & 31,00 & $29,52 \%$ \\
\hline 60,00 & 88,00 & 20,00 & $22,73 \%$ \\
\hline TOTAL: & $\mathbf{3 2 8 , 0 0}$ & $\mathbf{8 7 , 0 0}$ & $\mathbf{2 6 , 5 2 \%}$ \\
\hline
\end{tabular}

Analisando os resultados, pode-se compreender que houve prevalência de reduções de impedâncias junto aos resultados dos ensaios da Torre "D". Além disso, há preponderância estatística no que se refere às estacas de diâmetro de $50 \mathrm{~cm}$. Contudo, tendo em vista que as diferenças em relação às médias são baixas, pode-se concluir que o diâmetro das estacas não influenciou de modo significativo no que tange aos resultados do ensaio PIT.

\subsection{Redução de impedância de acordo com a geometria dos blocos}

$\mathrm{Na}$ Tabela 3, pode-se verificar as tipologias de blocos que apresentaram reduções de impedância em suas respectivas estacas, onde os mesmos métodos analíticos foram aplicados na torre "D", de acordo com a Tabela 4. 
Tabela 3. Geometria de blocos de coroamento que apresentaram reduções de impedância na torre "B"

\begin{tabular}{|l|c|c|c|c|c|}
\hline \multicolumn{7}{|c|}{ TORRE "B" } \\
\hline BLOCO & $\begin{array}{c}\boldsymbol{\emptyset} \\
\text { ESTACA } \\
(\mathbf{c m})\end{array}$ & $\begin{array}{c}\text { QUANT. } \\
\text { ESTACAS / } \\
\text { BLOCO }\end{array}$ & $\begin{array}{c}\text { TOTAL DE } \\
\text { ESTACAS }\end{array}$ & $\begin{array}{c}\text { TOTAL DE } \\
\text { ESTACAS COM } \\
\text { "PROBLEMA" }\end{array}$ & (\%) \\
\hline BLOCO 1 & 40,00 & 1 ESTACA & 82 & 9 & $\mathbf{1 0 , 9 8 \%}$ \\
\hline BLOCO 2 & 40,00 & 1 ESTACA & 2 & 0 & $\mathbf{0 , 0 0 \%}$ \\
\hline BLOCO 3 & 40,00 & 2 ESTACAS & 32 & 7 & $\mathbf{2 1 , 8 8 \%}$ \\
\hline BLOCO 6 & 50,00 & 2 ESTACAS & 18 & 7 & $\mathbf{3 8 , 8 9 \%}$ \\
\hline BLOCO 11 & 60,00 & 2 ESTACAS & 2 & 0 & $\mathbf{0 , 0 0 \%}$ \\
\hline BLOCO 13 & 40,00 & 2 ESTACAS & 4 & 0 & $\mathbf{0 , 0 0 \%}$ \\
\hline BLOCO 21 & 40,00 & 1 ESTACA & 3 & 0 & $\mathbf{0 , 0 0 \%}$ \\
\hline
\end{tabular}

Tabela 4. Geometria de blocos de coroamento que apresentaram reduções de impedância na torre "D"

\begin{tabular}{|l|c|c|c|c|c|}
\hline \multicolumn{7}{|c|}{ TORRE "D" } \\
\hline BLOCO & $\begin{array}{c}\boldsymbol{\emptyset} \\
\text { ESTACA } \\
(\mathbf{c m})\end{array}$ & $\begin{array}{c}\text { QUANT. } \\
\text { ESTACAS / } \\
\text { BLOCO }\end{array}$ & $\begin{array}{c}\text { TOTAL DE } \\
\text { ESTACAS }\end{array}$ & $\begin{array}{c}\text { TOTAL DE } \\
\text { ESTACAS COM } \\
\text { "PROBLEMA" }\end{array}$ & (\%) \\
\hline BLOCO 1 & 40,00 & 1 ESTACA & 87 & 18 & $\mathbf{2 0 , 6 9 \%}$ \\
\hline BLOCO 3 & 40,00 & 2 ESTACAS & 20 & 13 & $\mathbf{6 5 , 0 0 \%}$ \\
\hline BLOCO 6 & 50,00 & 2 ESTACAS & 14 & 8 & $\mathbf{5 7 , 1 4 \%}$ \\
\hline BLOCO 21 & 40,00 & 1 ESTACA & 3 & 1 & $\mathbf{3 3 , 3 3 \%}$ \\
\hline
\end{tabular}

Através destas tabelas, atribui-se que a maior parte das reduções de impedância em estacas ocorre junto aos blocos que possuem duas estacas sob os seus respectivos volumes, de maneira a incitar a análise do distanciamento entre os eixos das estacas existentes e, portanto, averiguar possíveis falhas executivas em virtude disso. Em face ao exposto, após examinar os relatórios das hélices contínuas monitoradas destes referidos elementos, verificou-se que não houve o alargamento ou então, a redução de seção de forma que se configure como perceptível ao ensaio PIT. Logo, em virtude destes dados, torna-se possível elucidar que pode ter sido detectado junto à execução das fundações alguns vícios construtivos, não se respeitando, portanto, a distância de, no mínimo, três vezes o diâmetro da estaca durante os procedimentos executivos na mesma data, de modo a obter maiores possibilidades de contaminação e desmoronamento do fuste no decorrer da realização da concretagem das estacas. Entretanto, não se pode ratificar tal informação, face a ausência de provas consistentes. 


\subsection{Pontos de sondagem que mais registraram incidências (reduções de impedância)}

Através da análise dos resultados dos ensaios PIT, foram sobrepostas as estacas que apresentaram as incidências e os pontos de sondagens, de maneira a apurar, de acordo com a proximidade, os pontos de sondagem com maiores ocorrências na obra de estudo, visando, desta forma, encontrar algum padrão de comportamento do solo, os quais se encontram dispostos na Tabela 5.

Tabela 5. Pontos de sondagem com maior número de ocorrências de reduções de impedância na obra de estudo

\begin{tabular}{|c|}
\hline $\begin{array}{c}\text { PONTOS DE SONDAGEM COM MAIORES NÚMEROS DE } \\
\text { REPETIÇÕES EM REDUÇÕES DE IMPEDÂNCIAS }\end{array}$ \\
\hline SPT $92=16$ REPETIÇÕES \\
\hline SPT $98=12$ REPETIÇÕES \\
\hline SPT $97=9$ REPETIÇÕES \\
\hline
\end{tabular}

\subsection{Perfil do solo}

O corte do terreno natural entre a cota de topo do SPT e a cota de arrasamento de estacas atinge uma média de $6,88 \mathrm{~m}$. Esse valor, por sua vez, é decorrente de escavações demandadas por garagens previstas no projeto arquitetônico da edificação. Assim, tendo em vista que o nível d'água médio encontrado no terreno, segundo as sondagens fornecidas, atinge 4,26m, verifica-se que foi obtido um nível superior ao corte médio executado no solo da obra. Logo, o nível d'água está acima da face de topo das estacas.

\subsubsection{Perfil médio do solo}

Obtendo por referência as sondagens da obra de estudo, restringe-se a amostragem para os pontos em que ocorreram o maior índice de reincidências no que diz respeito às reduções de impedância apresentadas no ensaio PIT (segundo a Tabela 5), para que, assim, torne-se possível traçar os perfis médios do solo junto às torres " $B$ " e " $D$ " e então, analisar onde as cotas de redução de impedância média tendem a resultar e, se, eventualmente, atingirão trocas de camadas de solos. Portanto, os perfis traçados podem ser visualizados por meio das Figuras 1 e 2. 


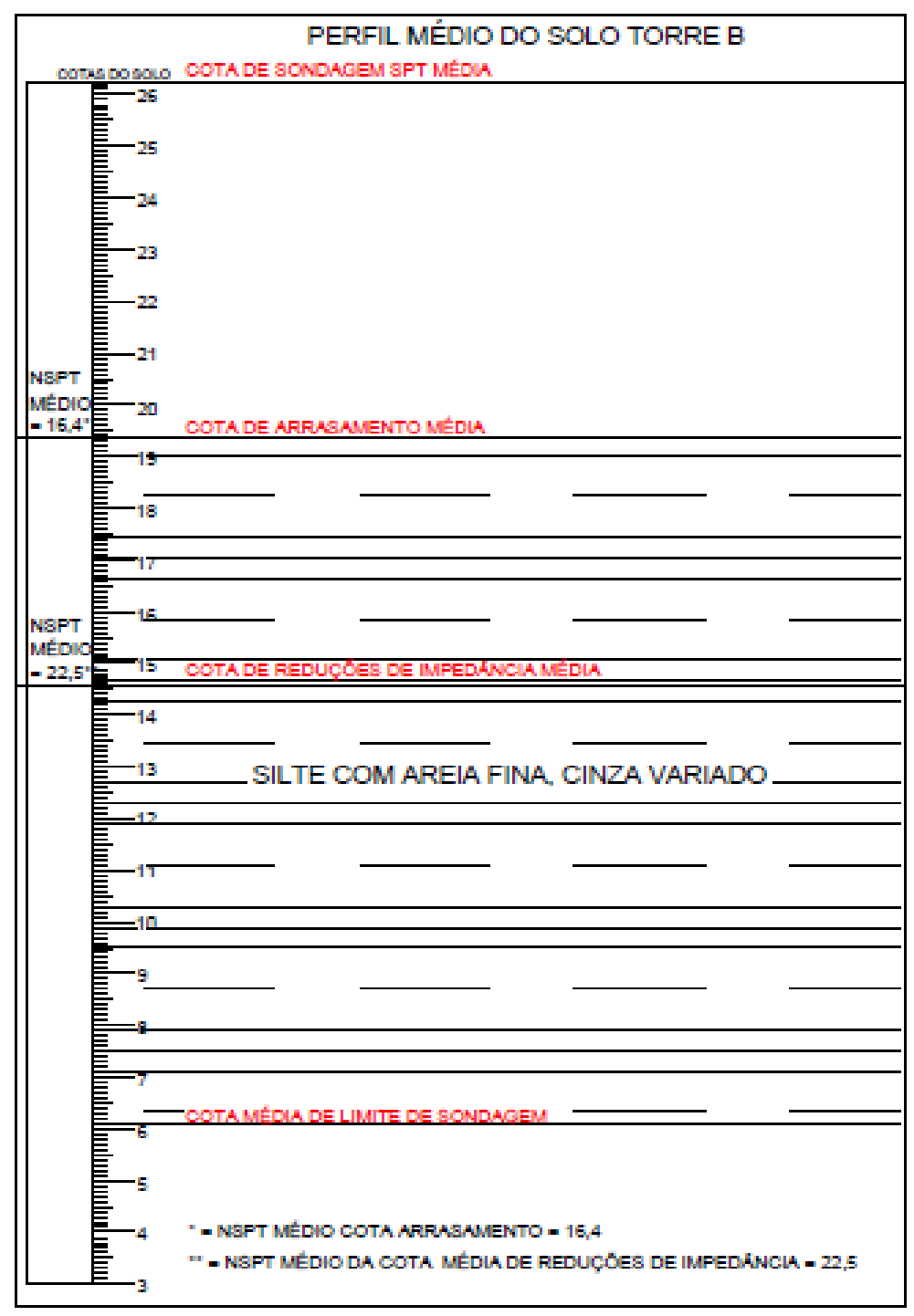

Figura 2. Perfil médio de sondagens da torre "B"

O perfil médio do solo da torre "B" está exposto a partir da cota de arrasamento média das estacas. Consequentemente, é constatável que a cota de reduções de impedâncias médias fornecidas pelos dados do ensaio PIT não está situada em região em que há alterações das camadas de solo. Em concordância com os ensaios SPT, o perfil do solo abrange somente o silte com areia fina. Para mais, as camadas superiores (níveis em que ocorreu o corte) detinham camadas de areia (arenito). Contudo, para o atendimento ao nível estipulado por meio do projeto de fundações, estas camadas foram eliminadas através de corte do terreno natural, dado que este se tornou necessário na medida em que há previsão de estacionamentos junto ao subsolo das torres. "D".

$\mathrm{Na}$ figura 3, representa-se o perfil médio de sondagens que compreendem a área da torre 


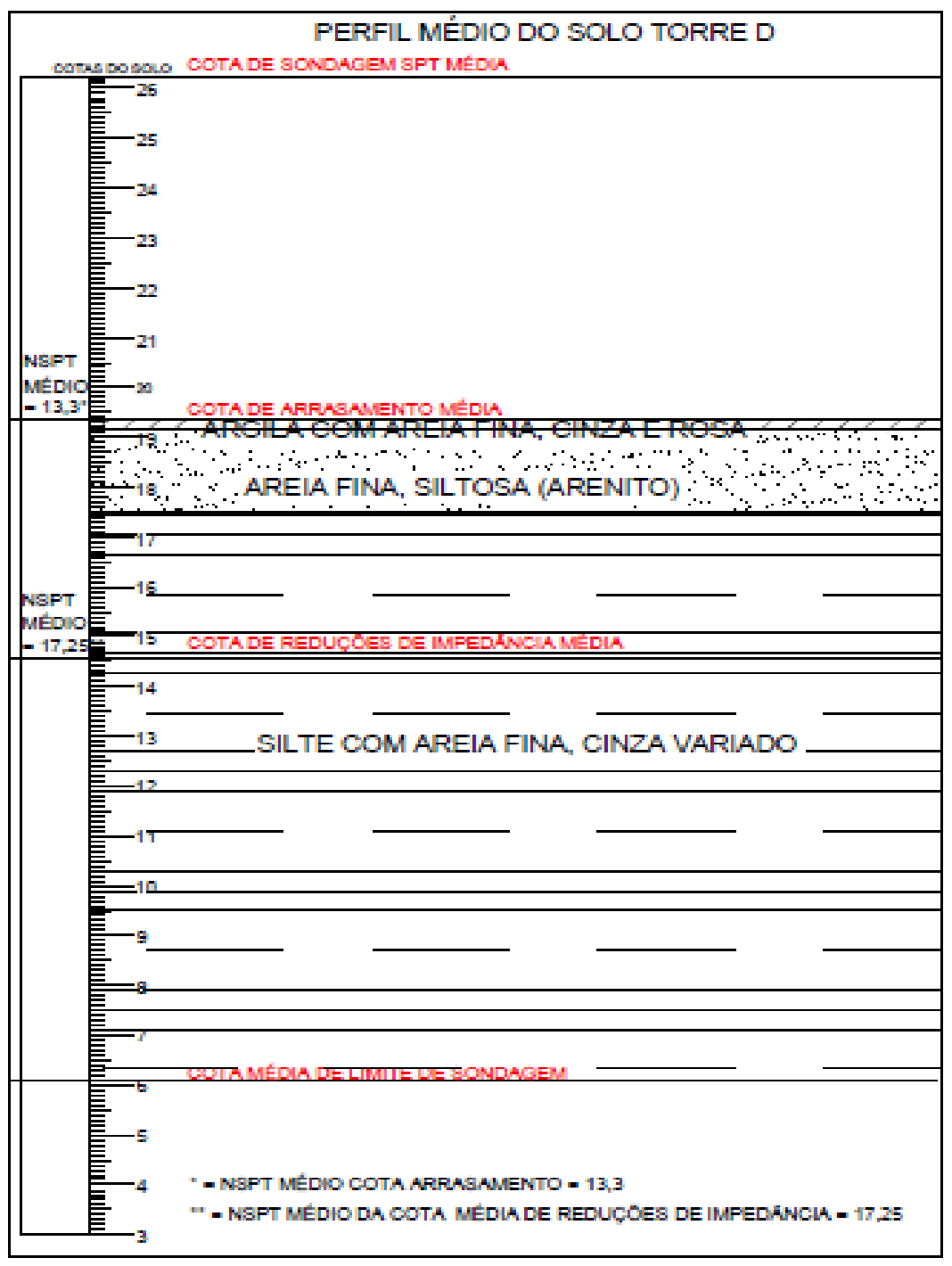

Figura 3. Perfil médio de sondagens da torre " $D$ "

Na figura 3 foram obtidas três camadas de solo nos elementos analisados, iniciando através da camada de argila, passando pela areia fina siltosa (arenito) e findando no solo composto por silte com areia fina, o limite das sondagens que representa o "impenetrável", de acordo com a NBR 6122 (ABNT, 2019). O nível d'água, o qual foi aferido durante a realização das sondagens, tornase inexistente em ambos os perfis médios apresentados, uma vez que se encontram acima da cota média de arrasamento das estacas. Todavia, na prática, houve uma alteração do nível d'água, o qual não se pode aferir após a execução das obras, visto que não foram executados novos ensaios geotécnicos no local.

$\mathrm{O}$ perfil médio da torre " $\mathrm{B}$ " apresentou menor índice de reduções de impedâncias em comparação com a torre "D", apontando um NSPT médio na cota 14,59 (cota média de reduções de impedâncias do ensaio PIT). Logo, através deste comparativo, pode-se constatar que o NSPT não fundamenta a discrepância nas reduções de impedância apontadas pelo ensaio PIT, esta que representam uma diferença na ordem de 173,91\%, (ou 17 unidades - segundo as tabelas 3 e 4) $248,57 \%$ entre as torres " $B$ " e " $D$ ". 


\subsection{Grau de compactação do solo em níveis em que há reduções de impedâncias apresentadas pelo ensaio PIT}

Dispondo por base a cota de arrasamento das estacas, desconta-se a profundidade apontada pelo ensaio PIT na qual há alguma redução ou interferência de sinais, para que, assim, possa-se estipular qual solo estivera contido no nível referido pelo gráfico. Diante disso, a tabela 6 remete o grau de compactação do solo junto ao nível em que se apresentaram as reduções de impedâncias (ou sinais) da obra de estudo.

Tabela 6. Grau de compactação do solo junto aos níveis que apresentaram reduções de impedância nas estacas da obra de estudo

\begin{tabular}{|l|c|c|}
\hline $\begin{array}{c}\text { COMPACIDADE DO SOLO JUNTO } \\
\text { AO NÍVEL DAS REDUÇÕES DE } \\
\text { IMPEDÂNCIA }\end{array}$ & QT. & (\%) \\
\hline Solo medianamente compacto: & 2,00 & $\mathbf{1 , 6 4 \%}$ \\
\hline Solo compacto: & 57,00 & $\mathbf{4 6 , 7 2 \%}$ \\
\hline Solo muito compacto: & 62,00 & $\mathbf{5 0 , 8 2 \%}$ \\
\hline
\end{tabular}

O NSPT médio junto ao nível em que se apresentam as reduções de impedâncias médias na torre "B" foi de 22,5, enquanto na torre "D", no mesmo nível (profundidade média das reduções de impedância do PIT), obteve-se 17,25. Portanto, o solo encontrado neste nível é definido como predominantemente compacto a muito compacto. Ainda, foi possível visualizar as múltiplas reduções de impedância em regiões em que ocorre a alteração do grau de compactação do solo, de compacto, para muito compacto, respectivamente.

\subsubsection{Cor do solo em reduções de impedância}

Por meio de técnica utilizada no item anterior, torna-se possível visualizar, através dos ensaios SPT, a cor do solo em nível em que há reduções de impedâncias, podendo-se assimilar a ocorrência de elementos ferrosos em preponderância nestes níveis, cuja presença, de modo geral, se correlaciona com a tendência a saturação deste solo. Na tabela 7 apresentam-se as cores do solo na cota de redução de impedância em cada ensaio individual, bem como seu percentual total.

Tabela 7. Cor do solo junto aos níveis em que há reduções de impedâncias nas estacas da obra de estudo

\begin{tabular}{|l|c|c|}
\hline COR DO SOLO JUNTO AOS NÍVEIS DAS RED. IMP. & QT. & (\%) \\
\hline Amarelo & 1,00 & $\mathbf{0 , 8 2 \%}$ \\
\hline Cinza & 92,00 & $\mathbf{7 5 , 4 1 \%}$ \\
\hline Rosa & 12,00 & $\mathbf{9 , 8 4 \%}$ \\
\hline Cor variada & 17,00 & $\mathbf{1 3 , 9 3 \%}$ \\
\hline
\end{tabular}

\subsubsection{Solo em reduções de impedância}

O solo da obra de estudo, até certo ponto, pode ser definido como homogêneo, dado que as camadas exprimidas pelo ensaio SPT remetem a uma mistura entre silte e areia. Face ao exposto, apura-se que ocorre a prevalência de um ou outro em determinadas sondagens. Diante disso, as reduções de impedâncias dos ensaios se apresentam de acordo com a tabela 8, a qual define o solo tipo de solo em que as mesmas ocorrem na obra de estudo: 
Tabela 8. Solo em nível de reduções de impedância na obra de estudo

\begin{tabular}{|l|c|c|}
\hline $\begin{array}{c}\text { SOLO JUNTO AO NÍVEL DAS REDUÇÕES DE } \\
\text { IMPEDÂNCIA ENCONTRADAS NO ENSAIO PIT }\end{array}$ & QT. & (\%) \\
\hline Argila fina, siltosa & 1,00 & $\mathbf{0 , 8 2 \%}$ \\
\hline Silte com areia fina & 63,00 & $\mathbf{5 1 , 6 4 \%}$ \\
\hline Areia fina, siltosa (arenito) & 58,00 & $\mathbf{4 7 , 5 4 \%}$ \\
\hline
\end{tabular}

\subsection{Armadura dos elementos inspecionados}

Através de uma verificação de projeto, foi possível verificar que a armadura calculada se apresentava pertinente em relação às recomendações das normas técnicas brasileiras. Então, buscou-se analisar se as possíveis anomalias apuradas junto aos ensaios PIT poderiam estar relacionadas com alguma falha executiva das armaduras. Dessa maneira, verificou-se que o projeto previa um detalhe executivo nas pontas das estacas, que é composto por um arqueamento das armaduras longitudinais, o qual é de praxe usual em projetos de estacas hélice contínua, uma vez que se motiva em função da armadura ser inserida logo após o concreto ser injetado (por pressão) pela perfuratriz, facilitando, dessa maneira, o processo de execução. Então, no que se refere ao atendimento ao projeto durante a etapa executiva da obra de estudo, pode-se visualizar a deficitária amarração dos estribos destas armações, assim como a diferença geométrica empregue no trecho final destas, correspondendo ao detalhe da ponta das estacas. Além disso, é possível visualizar também que, pelas falhas do acondicionamento dos materiais, há possibilidade de existência de nichos de concretagem em virtude do contato de matérias orgânicas (solo úmido, entre outros) com as armaduras, algo perceptível ao sinal do ensaio PIT durante o ensaio dos prismas em concreto armado. Tais incidências podem motivar, futuramente, na redução da vida útil dos elementos em aço, uma vez que há possibilidade da ocorrência de corrosão das armaduras junto ao solo umedecido.

\subsection{Armação realizada em obra e içamento de armaduras}

$\mathrm{Na}$ obra de estudo, verificou-se que o aço chegava cortado e dobrado diretamente ao canteiro de obras, sendo realizada somente a armação “in loco”. No entanto, os procedimentos de montagem (e amarração) aferidos na obra de estudo eram tecnicamente deficitários e, assim, causavam, durante o processo de içamento mecânico das armaduras, o desprendimento de diversos estribos. Por consequência, o concreto fresco e os elementos em aço entravam em contato com o solo próximo ao fuste na medida em que ocorre a inserção das armaduras das estacas parcialmente desintegradas. Diante disso, propicia-se a atribuição de reduções de impedância nos ensaios de integridade PIT.

\subsection{Elaboração de curva de gauss - profundidades de reduções de impedância encontradas nos ensaios pit da obra de estudo}

Com a finalidade de analisar os parâmetros das distribuições de probabilidade, utilizou-se da distribuição normal, fundamentando-se através da elaboração da Curva de Gauss acerca das reduções de impedâncias da obra de estudo. Assim, calculou-se a média das profundidades, para que, por sua vez, fosse calculado o desvio padrão. Diante disso, resultou-se em uma média de 4,78m no tocante ao nível médio das reduções de impedância, possuindo um desvio padrão de $1,15 \mathrm{~m}$.

Através da obtenção do desvio padrão de 1,15m, permite-se o cálculo da Curva de Gauss. Dessa maneira, transfigura-se possível detectar que a região que apresenta $68,2 \%$ das reduções de impedâncias está situada entre $3,62 \mathrm{~m}$ e $5,93 \mathrm{~m}$, sendo estes os níveis que representam a profundidade das interferências de sinais detectados junto ao PIT. Esses níveis coincidem com a maior parte das armaduras encontradas em obra (estas com $4 \mathrm{~m}$ de comprimento - armadura mínima 
de estacas hélice contínua). Desse modo, frente aos apontamentos realizados, podemos visualizar a Curva de Gauss na figura 4.

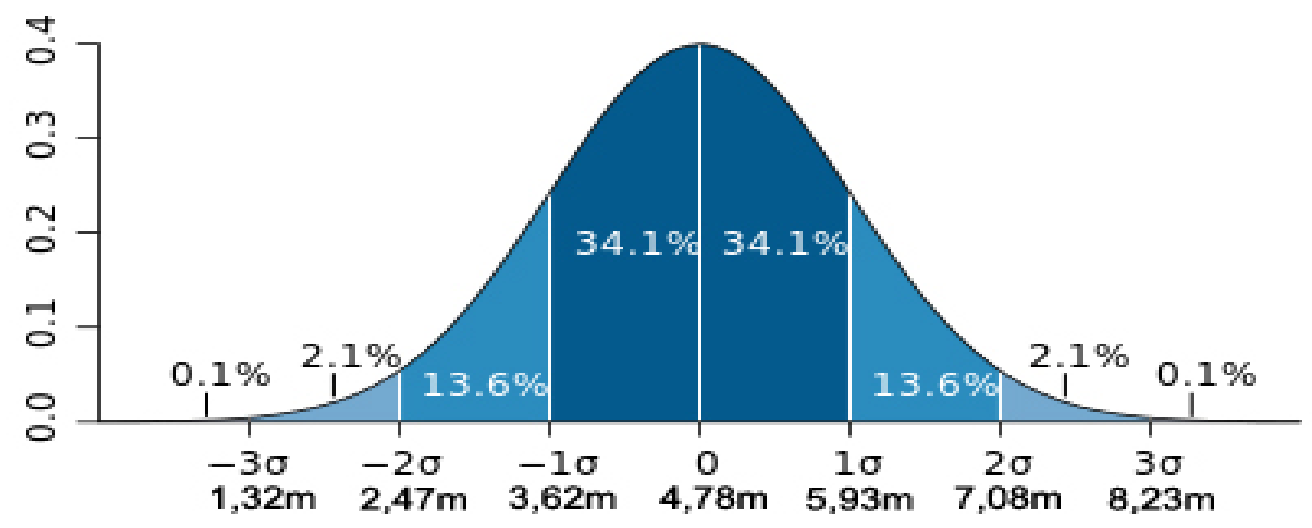

Figura 4. Curva de Gauss de profundidades em que há reduções de impedância, de acordo com os ensaios PIT, na obra de estudo

\subsection{Resultados do PDA (Prova de Carga Dinâmica) em estacas que apresentaram reduções de impedância}

As estacas que apresentaram divergências nos ensaios PIT foram designadas para o ensaio PDA, conforme as determinações do projetista geotécnico, para que, assim, fosse apurado se as reduções de impedância poderiam ser indícios de manifestações patológicas que pudessem vir a comprometer a segurança das fundações da obra de estudo. Assim, a empresa responsável pelo empreendimento estabeleceu que somente os gráficos que apresentaram maiores picos nos ensaios recebessem o ensaio de Prova de Carga Dinâmica, respaldando-se no aporte técnico do projetista geotécnico, ou seja, estes ensaios não representam a totalidade de estacas que apresentaram resultados desfavoráveis no PIT.

Nesse contexto, os resultados do PDA foram favoráveis, uma vez que, na obra de estudo, não se tornou necessária a realização de reforços estruturais ou qualquer alteração de concepção do projeto de fundações, cuja decisão foi tomada após a análise do projetista. Desse modo, concluise que os resultados do ensaio PIT não identificaram anomalias estruturais, afetando, tão e somente, o cronograma executivo de obras.

\subsection{Alterações previstas para a nova fase de obras}

De acordo com o responsável técnico pela terceira fase da obra (projeto futuro - torres com projetos similares), devido aos constantes "falsos positivos" dos ensaios PIT da obra de estudo, as novas armaduras das estacas hélice contínua chegarão montadas na obra, de modo que será eliminada a deficitária armação realizada por empresas terceirizadas, dado que ocorrera, durante o processo de içamento mecânico, a dessolidarização dos elementos armados, tal qual os estribos que frequentemente se soltavam das armaduras longitudinais. Além disso, objetiva-se adquiri-las obtendo solda junto aos estribos, minimizando-se, portanto, avarias decorrentes do içamento e da inserção de armaduras em estacas hélice contínua, representando, nesse contexto, a sequência de execução desta tipologia de estacas. 


\section{CONCLUSÃO}

Diante da análise de todos os dados coletados e avaliados, bem como o acompanhamento parcial dos processos executivos da obra de estudo, tornou-se possível verificar que o principal motivo para o acúmulo das reduções de impedâncias apresentados junto ao PIT decorre da influência das armaduras inseridas após a concretagem das estacas. Além disso, as falhas das armações e montagens realizadas "in loco" acabavam por fragmentar as armaduras (longitudinais e estribos), separando-as na medida que ocorria o içamento mecânico, propiciando, de tal maneira, o surgimento de reduções de impedância à medida em que o material era inserido ao concreto fresco, visto que os estribos e armaduras longitudinais (ambos desalinhados e com segmentos soltos) entravam em contato com as matérias próximas ao fuste, as quais são originadas pelo solo do terreno, de maneira que o cobrimento previsto em projeto também não seja atendido. Para mais, o acondicionamento destes insumos junto ao canteiro de obras também remete a tal diagnóstico, dado que as armaduras estavam, por vezes, parcialmente imersas ao solo e, portanto, partículas deste acabavam por ficar integradas às armaduras longitudinais e/ou estribos. Ademais, tais incidências favorecem o surgimento de manifestações patológicas ao médio e longo prazo, pois há maior probabilidade da ocorrência de corrosão das armaduras supracitadas em virtude da umidade do solo.

No que diz respeito ao nível d'água (após 24h), de acordo com as sondagens SPT, ele é praticamente onipresente em todas as estacas executadas, amparando-se, inclusive, a escolha pela hélice contínua. Aliás, observa-se que o solo, de modo geral, é relativamente homogêneo abaixo das cotas de arrasamento das estacas e, bem como possui certa compacidade, não caracterizando um solo mole em que há uma maior possibilidade do desmoronamento do fuste. Por fim, partiu-se para a verificação dos relatórios das estacas hélice continua monitoradas e, nos mesmos, não se pode constatar irregularidades. Dessa maneira, descarta-se a possibilidade de que a qualidade do concreto, alargamento ou redução de seção possam estar relacionados às reduções de impedância, uma vez que os dados fornecidos embasam tais ponderações.

Face às considerações supramencionadas, ratifica-se que o PIT corresponde, de certa forma, a um "falso-positivo" ou "falso-negativo" no que se refere à integridade estrutural, pois os resultados dos ensaios de provas de cargas dinâmicas não apresentaram discrepâncias ante ao projeto, estes os métodos mais precisos a fim de apurar o atendimento no que se refere a resistência prescrita junto ao mesmo. Logo, conclui-se que, na obra de estudo, foi verificado o emprego de vícios e falhas construtivas durante o processo de armação, tal qual falhas no acondicionamento das armaduras e a possível contaminação de fuste através do não cumprimento da NBR 6122 (ABNT, 2010) (vigente à época) em relação ao preconizado junto ao item F.7 (p. 53), em que "não se devem executar estacas com espaçamento inferior a cinco diâmetros em intervalo inferior a 12h". Contudo, apesar do exposto, não se concebe uma anomalia estrutural imediata, demandandose, apenas, a correta interpretação dos ensaios e o conhecimento geotécnico dos elementos constituintes do sistema.

Mediante a isso, sugere-se como nova possibilidade de investigação o estudo do comportamento padrão das reduções de impedâncias durante a interação solo-armaduras-concreto, de maneira a legitimar que os sedimentos oriundos do solo, estes incorporados às armaduras, tal qual este estudo de caso, e até a camada de oxidação superficial das mesmas, possam inferir em reduções de sinais junto ao ensaio de integridade PIT. 


\section{REFERÊNCIAS}

Alonso, R. (1991), "Previsão e Controle das Fundações". 2. Editora Edgard Blucher LTDA, São Paulo, Brasil.

Associação Brasileira de Normas Técnicas. (2013). NBR 15575-1: Edificações habitacionais Desempenho Parte 1: Requisitos gerais. Rio de Janeiro.

Associação Brasileira de Normas Técnicas. (1983). NBR 8036: Programação de sondagens de simples reconhecimento dos solos para fundações de edifícios. Rio de Janeiro.

Associação Brasileira de Normas Técnicas. (2020). NBR 6484: Sondagem de simples reconhecimento com SPT - Método de ensaio. Rio de Janeiro.

Associação Brasileira de Normas Técnicas. (2010). NBR 6122: Projeto e Execução de Fundações. Rio de Janeiro.

Associação Brasileira de Normas Técnicas. (2019). NBR 6122: Projeto e Execução de Fundações. Rio de Janeiro.

Azeredo, A. (1977), “O Edificio até a Cobertura. Prática de construção civil’. 2. Ed. Editora Edgard Blucher LTDA, São Paulo, Brasil, p. 178.

Eurocode 7. (1997). Geotechnical Design. EC7. Londres.

Hachich, W., et. al. (1998), “Fundações: Teoria e Prática”. Fini, São Paulo, Brasil., p. 758.

Junior, C. R.; (2017) “A impedância e sua importância na manipulação de sinais sonoros”. Disponível em:

http://compmus.ime.ups.br/sites/ime/usp.br.compmus/files/imped\%C3\%A2ncia\%20\%281\%29.D F>. Acesso em: 19 dez. 2017

Milititsky, J., Consoli, C., Schnaid, F. (2008), “Patologia das Fundações”. Oficina de Textos, São Paulo, Brasil., p. 208.

Rausche, F.; Likins G.; Kung S. R.; 1992-2016. "Pile integrity and analysis." [1992-2016]. Disponível em:

http://www.pile.com/reference/4thStresswave/PileIntegrityTestingAndAnalysis.pdf/>. Acesso em: 15 out. 2016

Schnaid, F., Odebrecht, E. (2012). "Ensaios de campo e suas aplicações à engenharia". 2. Ed. Oficina de Textos, São Paulo, Brasil., p. 224.

Velloso, D., Lopes, F. (2011). "Fundações. Volume 1 - Fundações Superficiais”. Oficina de Textos, São Paulo, Brasil., p. 240.

Velloso, D., Lopes, F. (2010). “Fundações. Volume 2 - Fundações Profundas”. Oficina de Textos, São Paulo, Brasil., p. 352. 